Review of Income and Wealth

Series 54, Number 3, September 2008

\title{
DOES POPULATION AGEING PROMOTE FASTER ECONOMIC GROWTH?
}

\author{
BY RAFAEL GÓMEZ \\ London School of Economics and Centre for International Governance Innovation \\ AND \\ PABlo Hernández de Cos* \\ Banco de España
}

Can divergent demographic trends account for differences in per capita output across countries? We address this question by offering evidence that the process of population ageing is positively and significantly related to cross-country economic performance. We define and estimate the effect of demographic change in two ways. First, a growing cohort of working age persons (15-64) as a share of the total population is found to have a large positive effect on GDP per capita. Second, an increase in the number of prime age persons (35-54) relative to the younger working age population (15-34) is found to have a positive but curvilinear effect with respect to per capita GDP. We find that changes in per capita GDP peak when the ratio of the prime-to-younger age population reaches an optimum of prime age workers for every younger aged worker. Beyond or below this optimal ratio, per capita output is lowered.

\section{INTRODUCTION}

"What will you do, when you have built all the houses, roads, town halls, electric grids, water supplies and so forth, which the stationary population of the future can be expected to require?" (Keynes, 1937, p. 100)

Official demographic projections suggest that many high-income economies are rapidly ageing and will start witnessing steady declines in population after the first decade of this century (Kosai et al., 1998; Greenwood and Seshadri, 2002). Though largely a by-product of economic development (Galor and Weil, 1996, 2000), the effects of population ageing on macroeconomic performance have been of interest to economic thinkers as far back as Malthus and later Keynes (1937), with most viewing the ageing process as detrimental to growth. This belief, in part, stems from the definition of population ageing, which usually refers to a growing share of older aged workers and dependants (those aged 60 plus) in the total population. But population ageing is in fact part of a longer term process of what could better be termed "demographic maturation." Missing, from the typically gloomy demo-

Note: We are particularly grateful to Susantu Basu, Olympia Bover, Morley Gunderson, Gabriel Pérez Quirós, Javier Vallés and two anonymous referees for their suggestions and the comments of seminar participants too numerous to mention at the Banco de España, London School of Economics, Policy Studies Institute, and University of Toronto. We gratefully acknowledge the financial support of the Banco de España. The helpful research assistance of Wanja Weiche, Kenny Sandorffy, Adrain Ferer. and Konstantinos Tzioumis is greatly appreciated.

*Correspondence to: Pablo Hernández de Cos, Banco de España, Directorate General Economics, Statistics and Research, Cl Alcalá 50, Madrid 28014, Spain (pablo.hernandez_de_cos@bde.es).

(C) 2008 The Authors

Journal compilation (C) 2008 International Association for Research in Income and Wealth Published by Blackwell Publishing, 9600 Garsington Road, Oxford OX4 2DQ, UK and 350 Main St, Malden, MA, 02148, USA. 
graphic scenarios is the transition from a youthfully dominated labor market to one full of more experienced workers; a process which occurs prior to the later-stage ageing process and which has the potential to improve, rather than dampen, economic performance. Estimating the effect that this process of population ageing has on economic output is the central aim of this paper. ${ }^{1}$

Until the late 1990s, most estimates of population demographics on economic output focused on a single causal mechanism: the so-called "demographic dividend." This is where falling birth rates cause the size of the working age population (15-65-year-olds) to increase faster than total population growth, producing a positive, though purely transitional effect on per capita growth rates but a permanent one on levels of GDP per capita (Bloom and Williamson, 1998). The demographic dividend is a direct effect akin to adding more labor inputs to an aggregate production function. The dividend can also alter output indirectly, through changes in savings rates, capital accumulation and labor force productivity; though the direction of these latter channels is more ambiguous given that savings behavior and individual productivity vary systematically by age of worker.

These aforementioned life-cycle effects highlight a second but no less important link between population ageing and economic performance. Since falling birth rates affect not only the size (Alesina et al., 2003) but also the structure of the working age population, a country with greater numbers of experienced workers will differ substantially from one that is younger, even if both have workforces that are of the same relative size. ${ }^{2}$ In particular, if we consider that labor force participation and productivity grow fastest and peak during the prime working ages of 35 and $54^{3}$ - when the balance between general and experiential human capital reaches its optimum - then the productive capacity of a society with a large fraction of prime age persons should be markedly different from one with many more younger or older labor force participants (Mincer, 1974; Lemieux, 2003).

Recently several authors have incorporated age structure into their growth modeling and have applied age structure effects empirically to account for the growth of developing economies (Bloom and Canning, 2003a) specific cases such as Ireland (Bloom and Canning, 2003b), and the rise of East Asian economies (Bloom et al., 1999; Mason et al., 2008). Most of these recent studies have found

\footnotetext{
${ }^{1}$ Our ability to estimate independent demographic effects stems from the fact that current age structure is itself determined by past fertility, making it predetermined with respect to current economic conditions (Feyrer, 2002).

${ }^{2}$ We are not using "size" here in the same way as Alesina et al. (2003) or Jones (2003). We focus only on the size of the working age population rather than size of market as measured by total population. The size of the population may actually play an important role in growth. Jones (2003) estimates that 10-20 percent of U.S. per capita growth from 1950 to 1993 is simply due to overall population growth.

${ }^{3}$ More precise estimates can be found if we consider the typical Mincer (1974) wage regression, where experience is entered along with its square to reflect the rising but diminishing returns of experience with respect to productivity. Recent empirical evidence suggests that wages grow fastest for workers with at least 10 years of experience, slowing down for workers with at least 20 years of experience and reaching a plateau for U.S. workers with roughly 30 years of experience (Krueger and Pischke, 1992). If workers earn their marginal product, then earnings equations imply a 50 percent difference between the productivity of a 20 -year-old worker as compared to that of a 50-year-old with the same formal level of schooling (Feyrer, 2002). This Mincerian regression evidence, though fast approaching its 35-year mark, is still considered by most labor economists as the most useful "workhorse" model of wage determination (Lemieux, 2003).
} 
significantly important effects on economic outcomes such as savings, productivity and growth associated with age structure changes. One exception was an earlier attempt by Bloom and Malaney (1998), whose work on Russia's dramatic drop in life expectancy following the collapse of the Soviet Union provided a window into how demographic shocks could potentially affect economic output. Their estimates suggested that the net effect of the drop in life expectancy, the decline in the rate of total population growth, and the even larger decline in the rate of growth of the working age population was to lower the annual rate of growth of income per capita in Russia by roughly one-third of one percentage point. Given that Russia's per capita income fell at an average annual rate of 9 percent during 1990-95, the authors concluded that demographic effects had been at most a small contributor to Russia's poor macroeconomic performance.

In this paper both the direct and indirect effects of demographic ageing are estimated using a large cross-country panel spanning the past four decades. In keeping with earlier findings, we show that there is a positive relation between the ratio of working age persons (those aged 15-64) over the total population and levels of per capita GDP. Specifically, we find that a 5 percent increase in the ratio of working age persons can account for roughly one-quarter of per capita GDP differences across countries over the course of a decade. This finding is fairly robust to specification changes and the use of the Arellano-Bond estimator that takes account of potential endogeneity and the role of biases in dynamic models with fixed effects (Nickell, 1981; Arellano and Bond, 1991).

Our work also suggests that an optimal ratio of prime age workers exists. Specifically, we find that the ratio of prime age persons (those aged 35-54) to the younger working age population (15-34) should exhibit positive but diminishing returns with respect to per capita GDP. We calculate that there is a turning point for most countries in maximum per capita output growth that occurs when there are roughly 0.950 workers aged $35-54$ for every single worker aged 15-34 (i.e. roughly one mentor for every mentored worker). Below or above this ratio, output is lower. This finding, however, was higher in the dynamic estimation partly because our sample included later time periods (a facet of using the lag and differencing procedure of dynamic estimation); and so the optimal ratio of prime age to youth is higher at 1.37 .

The remainder of the paper proceeds as follows. Section 2 examines the causal mechanisms linking demographic maturity to faster economic growth. It is here that a theoretical rationale for an optimal prime-age ratio is developed. Section 3 presents the empirical approach. Section 4 describes the data. Section 5 presents the results along with robustness checks. Section 6 concludes.

\section{Demographic Ageing and Economic Growth?}

\subsection{Maturity and the "Canonical" Growth Literature}

As noted above, demography is both a by-product and a cause of the process of economic growth; the latter of which is the focus of this paper. ${ }^{4}$ Before we

${ }^{4}$ Galor and Weil (1996) made fertility decline part of their feedback-loop model, whereby declines in fertility (brought about by rising women's wages) raise capital per worker, and hence growth. 
estimate how much of the observed variation in per capita growth across countries can be accounted for by differences in demographic age structure, we will first examine the potential effects of an ageing population through the lens of the neo-classical production function (Temple, 1999).

To fix ideas, consider the basic Solow-Swan production function with factors and output measured in per capita terms and augmented with human capital:

$$
y_{i t}=\left(k_{i t}^{\beta} h_{i t}^{\alpha}\right) A\left(l_{i t}\right)^{1-\alpha-\beta} .
$$

Here the impact of demographic maturity will depend on the adjustment of the determinants of per capita output-i.e. relative labor supply $l$, physical capital $k$, human capital $h$, and an index of technical efficiency $A$ - to changes in age structure.

The most obvious link between demography and output can be seen if we simply trace through the effect on relative labor supply $l_{i}$ of a constant or rising birth rate in period $t-1$ followed by a subsequent decline in period $t$ (i.e. the effect of a "baby boom" and "baby bust" on the economy). As a reference point consider the case of Japan, which as seen in Figure 1, follows this pattern fairly closely. In period $t$, the demographic transition which began a decade earlier in Panel A begins to have an impact over potential labor supply in Panel B, since an increasing ratio of working age persons (15-64-year-olds) over the total population increases $l_{i}$, which in turn positively affects $y_{i t}$. This is the positive first order effect of a demographic transition.

However, demographic transitions eventually affect not only the size, but also the structure of the working age population, playing a potentially important role in capital accumulation; both physical $k_{i}$ and human $h_{i}$. This is the second order effect of a demographic transition. ${ }^{5}$ In a country where the birth rate has fallen for any length of time, a predetermined age structure change will occur in the working age population a decade and a half later-or the earliest age at which most persons can begin working.

Under the standard life-cycle model, individuals smooth consumption over the course of their lives. Hence, they borrow when they are young and save when they are economically active, and in particular, save most when they are of prime working age. ${ }^{6}$ This implies that a demographic transition will have a positive impact on aggregate savings - and over the stock of capital per person - in that fewer dependants and a greater percentage of prime-age persons will increase relative savings and capital. An increase in savings brought about by the growth of the working age population should therefore have a positive effect on output per capita.

The link between age structure and human capital accumulation centers on education and learning-by-doing, two factors essential in fostering productivity

${ }^{5}$ To see this more clearly, imagine two countries sharing working age populations of the same relative size. Both are equally mature in the sense that both share the same ratio of working age persons. The first order effect should therefore be identical. However, one country, by virtue of having had more recent falls in its fertility rate, has a greater share of young workers than the other. Two workforces of the same relative size may therefore be composed of a greater share of either young (15-34) or prime-age (35-54) workers.

${ }^{6}$ See Modigliani (1986) and Modigliani and Ando (1963) for classic references in this regard. 
Panel A: Live Births in Japan 1950-2000

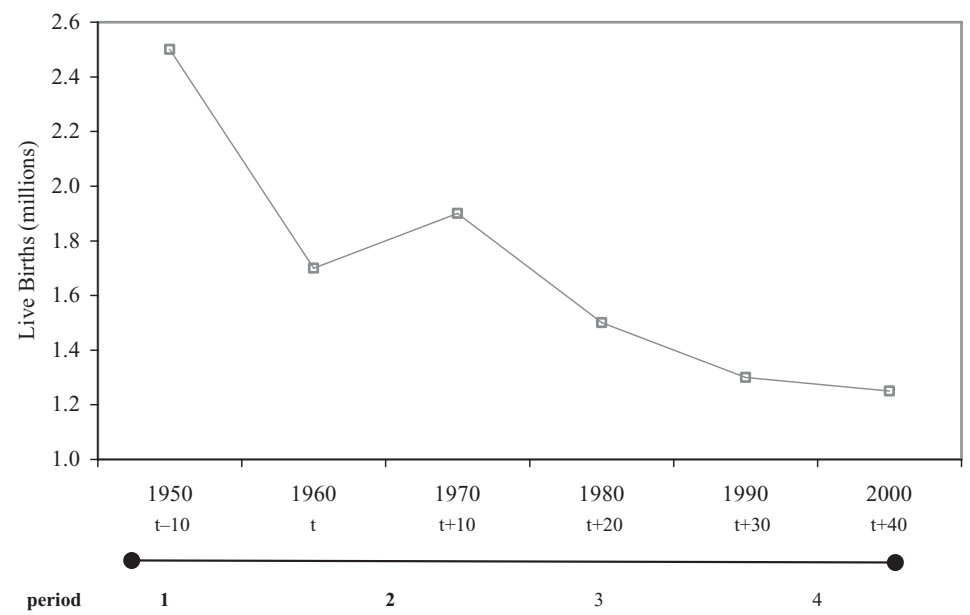

Panel B: Japanese Working Age Structure 1950-2000

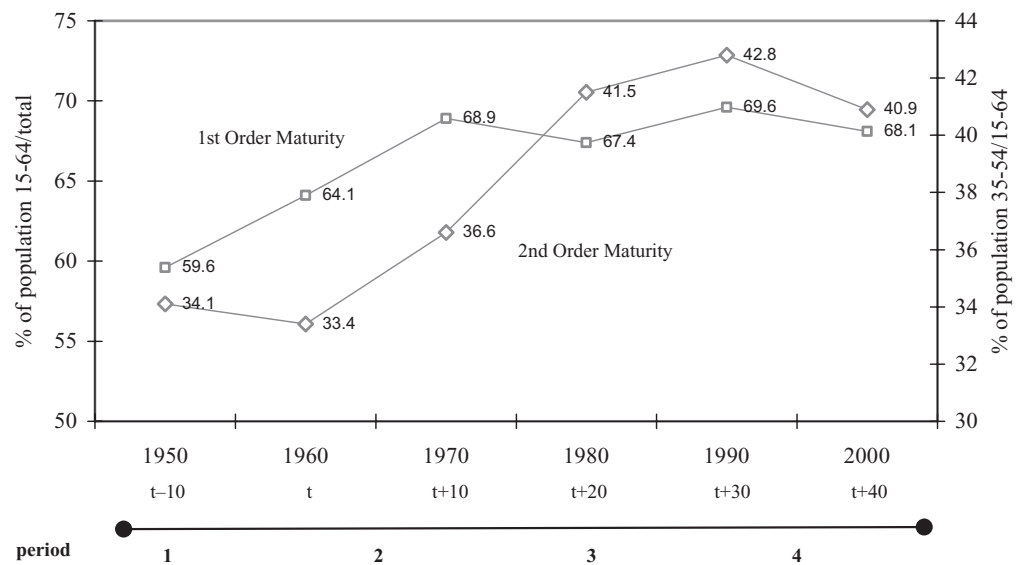

Figure 1. The Effect of Demographic Transition on Population Age Structure

growth. The stock of individual human capital peaks when the balance between formal education and experience reaches its optimum. ${ }^{7}$ This tends to happen sometime during the prime working ages of 35 and 54, after which wages stop growing and as workers transition into retirement. An economy with a large cohort of prime age workers should therefore be more productive than an economy populated by younger workers.

This type of "Mincerian" argument also implies that a turning point should be observed with respect to output per person, whereby too few workers at the younger end of their working lives should be associated with fewer prime age

${ }^{7}$ Fougere and Merette (1999) also suggest that under a situation of scarce employment, incentives to human capital investment increase. 
workers in the future and hence slower output growth (Willis, 1986; Card, 1999). Firm-level observations simultaneously reinforce and attenuate this view. Not only do firms require workers with formal education, they also require the right combination of youth, experience and seniority; highlighting the need for an optimal rather than a strictly greater number of prime age workers in order to maximize output (Lazear and Freeman, 1996). Finally, with regard to the potential impact of ageing on technical efficiency $A$, endogenous growth models allow for the introduction of several links between demography and technology. At the macro-level, some authors argue that new entrants in the labor market are the main channel for the creation of new jobs and innovation (Simon, 1986; Ermisch and Joshi, 1987; Shimer, 2001; Jones, 2003). At the micro-level, evidence suggests that although the capacity to invest in new technology is significantly constrained by age, technological adoption within firms may actually be accelerated, rather than hindered, by the presence of older workers (Weinberg, 2002).

\subsection{Is there an Optimal Ratio of Prime Age Workers that Maximizes Growth?}

The evidence discussed above suggests that economies may benefit from having relatively more experienced workers in the population, but only up to a point, since a mix of young and older workers is likely to produce the most productive work environment. The reason has to do with skill complementarities that cannot be solved by simple wage adjustments; i.e. paying younger human capital less than experienced human capital will not solve the problem since mature and young human capital do different things. Experienced workers are associated with lower monitoring costs, have greater firm specific human capital and more skills learned on the job. Young workers, on the other hand, bring with them new ideas and general human capital embodied in formal education. Imperfect substitutability between the human capital of young and older workers may therefore be a key feature of aggregate production and may even explain why per capita output does not converge instantaneously as some open-economy growth models suggest (Kremer and Thomson, 1998). Micro-level evidence drawn from the field of personnel economics reinforces this view (Lazear and Freeman, 1996). Firms typically have a bias towards more experienced workers, all things equal, but are ultimately concerned with the relative level of prime-age human capital than the absolute level, since they recognize that some balance between youth and experience is required.

In order to explore the implications of this reasoning a bit further, consider a variant of equation (1), where an economy consists of firms that produce output $Y$ with technology $A$, but instead of utilizing one type of labor, utilize experienced/ prime age $L^{m}$ and young $L^{y}$ labor inputs,

$$
Y=\left(K^{\beta} H^{\alpha}\right) A\left(L^{m}+\theta L^{y}\right)^{1-\alpha-\beta},
$$

where $\theta$ is the marginal product of $L^{y}$ relative to $L^{m}$. If workers were perfect substitutes then relative productivity would be $\theta=1$, and there would be no single mix of both labor inputs that would maximize output. In equilibrium with perfect substitutability, firms would be indifferent to the proportional mix of young and 
prime age labor employed. However, if experienced labor is more productive $\theta<1$, and both young and prime age human capital are necessary in production (e.g. there is a need for both mentors and the mentored), then firms maximize output using a production function similar to that found in Neumark (1988). Holding $K$ and $H$ fixed and focusing only on changes in labor supply:

$$
Y=A\left(L^{m}+\theta L^{y}\right)-\delta\left(L^{y} / L^{m}\right),
$$

we identify $\delta$, which is simply the inverse of the relative productivity ratio and is akin to an "experiential bias"; a coefficient capturing the desire of firms (other things equal) for prime age workers. In this set-up, however, employers care about the relative level of $L^{m}$ rather than the absolute level since they recognize that some balance between youth and experience is required. Maximization of (3) implies

$$
\theta=\left(\delta / L^{m}\right) /-\left[\delta \cdot L^{y} /\left(L^{m}\right)^{2}\right]
$$

Here the (falling) marginal product from one additional unit of $L^{y}$ is not fixed, but depends on the relative level of $L^{y}$.

The impact of this type of production structure on output change is captured in Figure 2, where the effect of adding prime age workers follows an inverted U pattern. A country populated with an optimal level of prime age human capital $L_{o}^{m}$ relative to the younger working population will grow faster than a country that has either too few $L_{1}^{m}$ or too many $L_{2}^{m}$ experienced/prime age workers. Note, as well, that birth rate falls are a precondition for relative increases in the ratio of prime

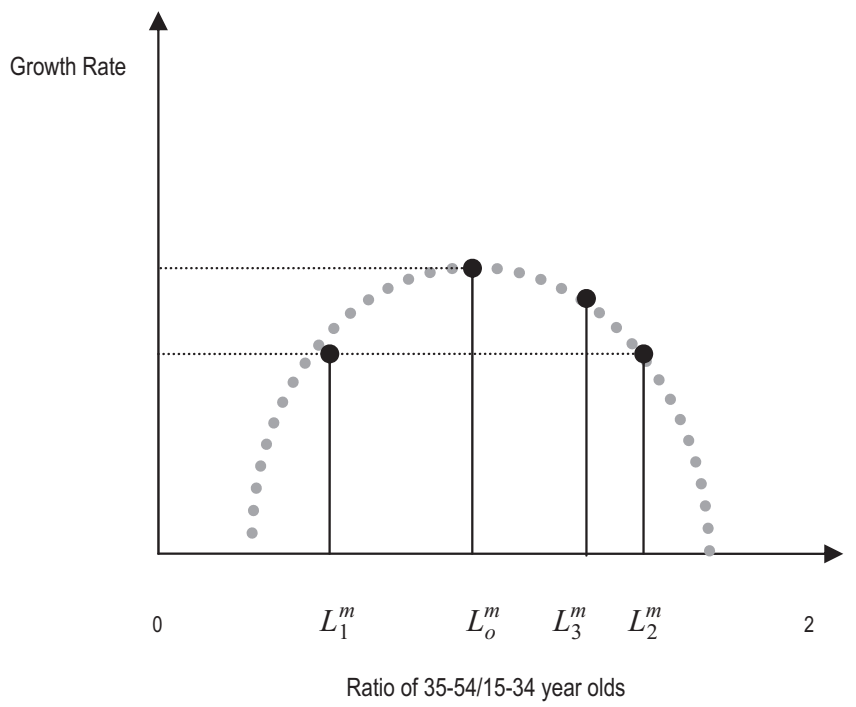

Figure 2. The Hypothesized Effect of Second Order Maturity on Medium Term Growth Rate 
age workers, but that persistent birth rate declines will eventually push countries past the optimal prime age ratio, and may ultimately dampen rather than promote growth.

The intuition developed above does not preclude cross-country heterogeneity, as $\delta$ may vary across firms, industries or different economies; i.e. economies with a higher $\delta$ will optimize by employing more $L^{m}$ at the expense of $L^{y}$. Why would firms or economies differ in their need for older workers? Two reasons seem plausible. First, the more idiosyncratic are firm or country experiences, the higher will be the experiential bias $\delta$, since prime age workers are likely to have better knowledge of these idiosyncratic details. Labor market idiosyncrasies would presumably be increased the greater the service orientation of an economy; e.g. banking and legal services are highly tailored and differentiated and require more experienced workers to deliver them. Second, to the extent that on-the-job skills are relatively more important than skills learned in formal education, experienced workers will again be more desired since there will be a greater need for "mentors" and senior workers fill that role better than younger ones. To the extent that an economy is younger and more manufacturing based-i.e. the economy requires labor to simply stamp out more widgets - so the bias would tilt more to youth than experience. Changes in the structure of the working age population, rather than in the size, can therefore affect output in this model by increasing the relative supply of $L^{m}$ relative to $L^{y}$.

To think of a real world example, consider the case of an increase in young workers entering the labor market - as occurred in the late 1970s in the U.S. as the peak of the baby boom generation (born in the early 1960s) entered the labor market. Because of imperfect substitutability between young and prime age labor inputs, firms will work to keep the optimal ratio of young and prime age labor intact. ${ }^{8}$ Firms may hire fewer younger workers and/or divert resources away from production to monitoring. The logic here is that an older worker may be able to supervise/mentor two junior workers properly but the ability to supervise effectively diminishes as the number of junior workers increases. Now consider the opposite case of a fall in the relative supply of youth labor-as occurred in the early 1990s in the U.S. as the baby bust generation (born in the 1970s) began entering the labor market. Here again, an economy may suffer since too few junior employees relative to prime age workers will impede the upward flow of new knowledge and new ideas. Firms that are faced with fewer younger recruits may therefore be forced to downsize throughout the middle ranks of the organization (i.e. lay off middle aged workers) in an effort to preserve the optimal prime age-youth labor mix.

In both cases, if we assume that a firm works to keep its labor mix at an optimum, output may fall as a result of a change in the relative supply of mature and/or youth labor. At the cross-country level, this model implies that second order maturity may not always be associated with improved economic performance. Specifically, a greater cohort of prime age workers unambiguously benefits a country's output per capita if firms are already below the optimum prime age-

\footnotetext{
${ }^{8}$ Assuming constant attrition rates for both young and old workers.
} 
youth ratio ${ }^{9}$ if economic experiences are highly idiosyncratic; or if on-the-job skills are relatively more important than general skills to the economy. Otherwise, most countries prefer a balance of young and prime age human capital.

\section{EMPIRICAL APPROACH}

The theoretical discussion above has highlighted two testable propositions related to demographic ageing and economic performance:

1. That the first order effect of a demographic transition should have an unambiguously positive impact on economic output; hence the coefficient associated with the ratio of working age persons aged 15-64 over total population should always have a positive sign with respect to per capita output.

2. That the second order effect of a demographic transition implies the ratio of prime age-to-young working age persons in the population should display an optimum with respect to economic output; thus, increases in the proportion of working age persons aged 35-54 relative to the younger working age population (aged 15-34) should exhibit positive but diminishing returns with respect to per capita economic output.

To test these two propositions we initially make use of the convergence equation, popularized by Barro and Sala-i-Martin (1995) and Mankiw et al. (1992), which follows a specification like the one below:

$$
\Delta y_{i t}=\beta_{1} y_{i t}+\beta_{2} X_{i t}+\beta_{3} D_{i t}+u_{i t},
$$

where $\Delta y_{i}$ is the growth rate of log real per capita GDP for country $i$ between time $t$ and time $t+1$, and is regressed against $y_{i t}$ the log of per capita GDP for country $i$ at time $t$, a vector of initial period determinants of growth $X_{i t}$, our measures of first and second order demographic effects and $u_{i t}$, the error term. Because of the panel nature of our data, we are able to assume that the error term for the corresponding $i$-th country in the $t$-th time period is made up of three components: one country-specific, one time-specific, and a remainder which is truly random:

$$
u_{i t}=v_{i}+\lambda_{t}+\varepsilon_{i t} .
$$

Applying standard fixed effects (within-group) estimation with period dummies to (5) will wipe out the fixed error component and allow one to obtain coefficients on the exogenous variables which do not suffer from bias due to omission of relevant individual attributes. Such an empirical framework can be used to test for conditional convergence, which states that the rate of growth between two periods is a decreasing function of initial levels of income per capita and distance to the steady state. The vector $X_{i t}$ therefore controls for differences in the steady state across countries, which is generally proxied by the capital stock $k$ (if available), or share of output devoted to accumulated physical $s_{k}$ capital, and

\footnotetext{
${ }^{9}$ Conversely, if firms are already past the optimum, they benefit from a falling rather than a rising ratio of prime-age workers.
} 
the level of human capital $s_{h}$, and a variable capturing the growth rate of population $\dot{N}$, the exogenous rate of technological progress $\dot{\theta}$, and capital depreciation rates ( $\sigma_{k}$ and $\sigma_{h}$ assumed to be equal). ${ }^{10}$

Unfortunately, as first pointed out by Nickell (1981), a fixed effects growth model of the type presented above suffers from an important drawback in that estimations are liable to lead to biased coefficients in dynamic models. Moreover for a typical panel data set like ours - with a rather small number of time periods relative to individual observations - biases of the Hurwicz type are most serious. To correct for these biases, a difference-GMM estimator-proposed by Arellano and Bond (1991) — using lags of the level of the dependent variable and differences of the exogenous variables is implemented.

Difference-GMM exploits the dynamic nature of panel data sets by utilizing the moment conditions with lagged values of covariates. The moment conditions imply that instruments for endogenous variables need only be predetermined (weakly exogenous) and not strictly exogenous to the empirical model. All our key explanatory variables, including our age-structure population measures, are predetermined with respect to our dependent variable and hence fit well with the Arellano-Bond estimator. Additionally, difference-GMM allows one to account for any persistence of GDP growth over time by using the lag of the dependent variable as a right-hand side control. In contrast, traditional instrumentalvariable-fixed effects estimation requires strict exogeneity of instruments and would yield inconsistent coefficient estimates with a lagged dependent variable. The Arellano-Bond dynamic panel-data estimator is therefore applied to a second empirical model of the form:

$$
y_{i t}=\sum_{j=1}^{p} \beta_{1} y_{i, t-j}+\beta_{2} \cdot \Delta X_{i t}+\beta_{3} \cdot \Delta D_{i t}+v_{i}+\lambda_{i}+\varepsilon_{i t},
$$

where $y_{i t}$ is the log of per capita GDP in country $i$ at time $t, y_{i, t-j}$ the dependent variable with lag operator(s); $X_{i t}$ is the set of first differenced non-demographic explanatory variables including average level of schooling $s_{h}$, capital stock $k$ (where available $)^{11}$ and/or the investment share of GDP per capita $s_{k}$, and a measure of rate of population growth, rate of technological change and rate of capital depre-

\footnotetext{
${ }^{10}$ An equation like (5) can be derived from the augmented Solow model seen in (1) with constant returns to scale, but is also consistent with some endogenous growth models that predict different forms of convergence to the steady state. In this paper we are not interested in validating different models of economic growth. Instead we use this generic specification because it captures most of the common factors that have traditionally been considered as determinants of growth in the empirical literature (Temple, 1999) and because it allows us to treat population age structure as an added component of the steady state. Our intention, therefore, is to estimate a version of (2) with fixed effects.

${ }^{11}$ Unfortunately a consistent capital stick dataset is only obtained up to Penn World Table 5.6 (not 6.1). Hence the year by year data spans from 1965 to 1992, so for each country this has been "translated" into four data points from 1960 to 1990, in jumps of 10 years, as follows: the first data point of each country (normally 1965, but not always) is assigned to 1960. For successive points, the average of that year and the two years above and below is taken. For example, for the 1980 data point, the average of the data from 1978 to 1982 was taken. If one of the data points was not available (for example, if there is no data for 1992), the average was taken for only three or one data points (that is, if 1992 is missing, the average from 1989 to 1991 was used; if 1992 and 1991 were missing, the data for 1990 was used, no averaging).
} 
ciation, $(N+\theta-\sigma)$; and $D_{i t}$ is the differenced pair of population age structure variables measuring the size of the working age population and prime age-toyouth ratio. ${ }^{12}$

The vector $D_{i t}$ includes the variable WORKING_AGE, which captures the first-order ageing effect defined as:

$$
W O R K I N G_{-} A G E_{i t}=\frac{\sum_{15}^{64} W_{i t}}{\sum_{0}^{99} N_{i t}} \text {. }
$$

This is a ratio measuring the number of potentially active persons (15-64), $W$ over the total population, $N$. The expectation is that countries with higher shares of 15-64-year-olds will experience faster growth and be associated with higher per capita output.

A second measure PRIME_YOUTH uses the number of prime age persons aged $35-54, w$, over the number of young working age persons aged 15-34, $g$, to measure the following ratio:

$$
\text { PRIME_YOUTH } H_{i t}=\frac{\sum_{35}^{54} w_{i t}}{\sum_{15}^{34} g_{i t}} \text {. }
$$

This variable recognizes that the productive capacity of a society with a high fraction of more experienced prime age persons relative to younger less experienced workers is generally higher than that of a society with many young labor market entrants. Beyond a certain threshold, however, having too many or too few older workers may actually dampen growth. To capture the non-linearity inherent in second-order maturity, our preferred estimate preserves the PRIME_YOUTH variable as a ratio along with its square PRIME_YOUTH_SQ. ${ }^{13}$

\section{DAtA}

We employ a composite dataset made up of versions 5.6 and 6.1 of the Penn World Tables, and demographic data provided by the United Nations' Population Division. The Penn World Tables, which Summers and Heston (1991) and Heston et al. (2002) have been collecting for more than a decade, includes observations from 1950 to 2000 for approximately 144 countries. It is used primarily for its PPP

\footnotetext{
${ }^{12}$ If using an unbalanced panel, a set of time dummies would also be included.

${ }^{13}$ First and second order population ageing effects as measured by (7a) and (7b) and estimated as in (5) and (6), will test whether there is a significant first order effect and allow us to more accurately identify the non-linear effect of the PRIME_YOUTH variable implied by the Mincerian and personnel economic literature surveyed. Finally, by controlling for the stock of physical capital and technical progress, the two primary demographic channels above are zeroing in on ageing effects arising from human capital and firm level maturity described in Section 2.
} 
adjusted measures of income per capita across countries. Version 5.6 of Penn Tables, which ends in 1990, is used for its real capital stock series available for 61 countries. A second data source, the United Nations World Population Prospects (United Nations, 1998), provides corresponding demographic data for 160 countries from 1950 to 2000 - with age structure and population projections running until 2050.

Table 1 provides an overview of the patterns of changing age structure observed across countries over the past 40 years. The table documents changes in our key measures of population ageing; i.e. the share of the working age population (15-64) over the total population, the proportion of persons aged 35-54 over the size of the potential working age population, and the ratio of prime age (35-54) workers over young (15-34) workers. The first row of the table documents the all country total and shows a positive shift in first order maturity from 1960 to 2000. The percentage of persons aged 15-64 increased from 56.4 in 1960 to 60.9 in 2000. The row also identifies the $U$ shaped pattern in prime age structure brought about by the delayed effect of the post-war baby boom, which from the 1960s to 1980s made many national working age populations younger than their historical averages.

A comparison of age structure patterns for different country groupings - such as between OECD and non-OECD countries in row 2 and in Figure 3 -shows that the global average masks a marked diversity of age structures. Countries in the OECD have had larger PRIMEAGE ratios from the 1960s onward. Despite having grown younger in the 1970s and 1980s, the OECD has never approached levels found in the non-OECD world. In 2000, for example, 43 percent of the OECD's working age population was aged $35-54$ and there were 1.3 prime age workers for every 15-34-year-old, versus 34 percent and 0.75 for the rest of the world respectively. The countries in row 6 also show the heterogeneity that is masked if we look only at row 1 .

Rows 3-5 of Table 2 illustrate what are probably more interesting facts about age structure over the past 40 years: the dramatic difference in the proportion of prime age persons between countries with high and low indices of civil liberties and individual freedom, the consistently higher proportions of prime age workers in more equal societies (as measured by the GINI ratio) and in countries with greater political participation (as measured by the percentage of voting age population who casts a vote). By many measures, it seems, being older as a society carries with it a number of benefits.

\section{RESUlts}

We begin with a fixed-effect (within group) estimation of equation (5) using a balanced panel of 84 countries. ${ }^{14}$ The sample is split into four ten-year periods

\footnotetext{
${ }^{14}$ Countries are often missing data and hence drop out of our sample. Of the 106 countries that had complete LHS data, 22 were either missing two or more key pieces of RHS data or were categorized as having low quality data by Summers and Heston. We therefore chose to focus on a high quality balanced sample.
} 


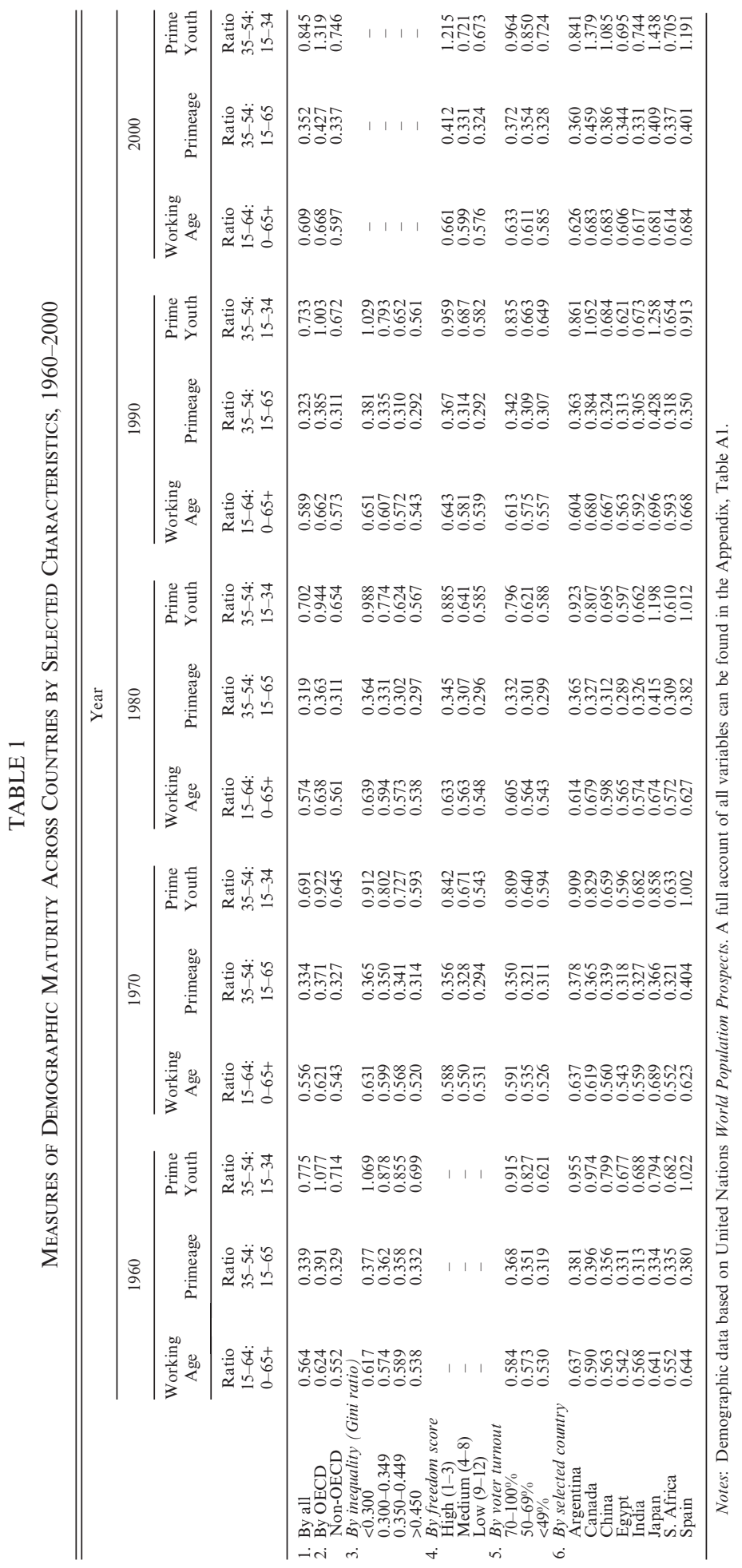


Panel A: Ratio of Potentially Active Population (15-64) over Total Population (0-65+)

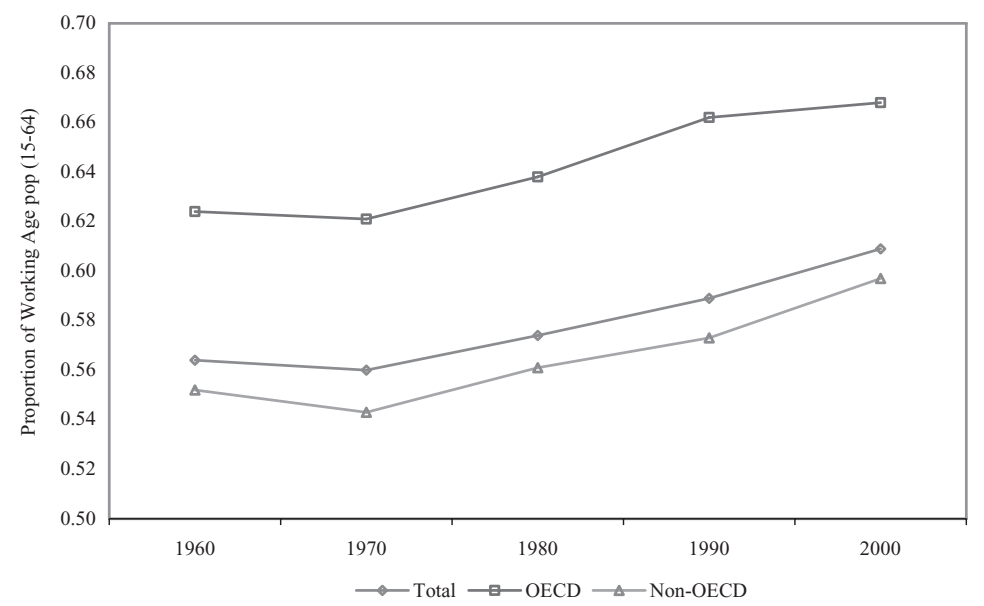

Panel B: Ratio of Prime age (34-54) to Young Working Age Population (15-34)

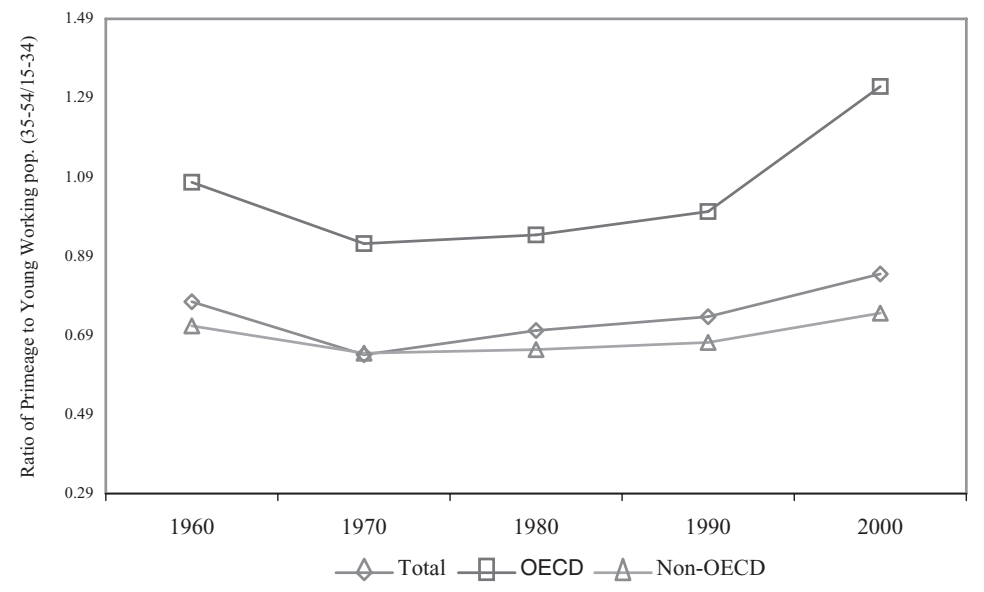

Figure 3. Age Structure across Countries, 1960-2000

beginning in 1960 and ending in 2000. This gives us a total of 336 observations. When using our capital stock variable in place of investment share of GDP, we are restricted to just three ten-year time periods and 52 countries; as a consequence our sample size is 208 observations. Our dependent variables are the percentage change in GDP per capita observed over a ten-year period and the level of GDP per capita at the end period. ${ }^{15}$ For our growth equations, the values of our steady state and

${ }^{15}$ The decision to employ a 10 year period for growth rate estimates is threefold. First, demographic variables are typically collected by a national census prepared every decade, while intervening figures are often obtained by interpolating two consecutive census periods. Second, it is difficult to find significant changes in the demographic variables in shorter time periods. Finally, 10 year growth rates also smooth out any short-run output fluctuations. 
TABLE 2

Fixed-Effect Estimates of Demographic Ageing and Economic Output Across Countries, 1960-2000; Dependent Variable(s): 10 Year Compound Growth Rate of Log GDP PER CaPITA (Growth) AND LeVel of Log REAL GDP PER CAPITA (LEVEL)

\begin{tabular}{|c|c|c|c|c|}
\hline \multirow[b]{2}{*}{ Independent Variables } & \multicolumn{4}{|c|}{ Within Group Estimates } \\
\hline & Growth (1) & Level (2) & Growth (3) & Level (4) \\
\hline 1. $\operatorname{Ln}\left(Y_{t-1}\right)$ & $\begin{array}{l}-0.374 * * * \\
(-14.61)\end{array}$ & $\begin{array}{l}0.625 * * * \\
(14.65)\end{array}$ & $\begin{array}{l}-0.560 * * * \\
(-8.59)\end{array}$ & $\begin{array}{l}0.813^{* * *} \\
(13.95)\end{array}$ \\
\hline 2. $\operatorname{Ln}\left(S_{k, t-1}\right)$ & $\begin{array}{l}0.094^{* * *} \\
(3.10)\end{array}$ & $\begin{array}{l}0.269^{* * *} \\
(7.25)\end{array}$ & $\begin{array}{l}0.148^{* * *} \\
(3.02)\end{array}$ & $\begin{array}{l}0.375^{* * *} \\
(9.20)\end{array}$ \\
\hline 3. $\operatorname{Ln}\left(S_{h, t-1}\right)$ & $\begin{array}{l}0.010 \\
(0.29)\end{array}$ & $\begin{array}{l}0.267 * * * \\
(6.72)\end{array}$ & $\begin{array}{c}-0.002 \\
(0.06)\end{array}$ & $\begin{array}{c}-0.003 \\
(0.06)\end{array}$ \\
\hline 4. $\operatorname{Ln}(N+\theta+\sigma)$ & $\begin{array}{l}-2.226 \\
(-0.78)\end{array}$ & $\begin{array}{l}-2,329 * * \\
(-2.44)\end{array}$ & $\begin{array}{r}8.17^{*} \\
(-1.98)\end{array}$ & $\begin{array}{r}9.13^{*} \\
(-1.94)\end{array}$ \\
\hline 5. Ln WORKING_AGE ${ }_{t-1}$ & $\begin{array}{l}0.539^{* * *} \\
(2.50)\end{array}$ & $\begin{array}{l}2.32^{* * * *} \\
(9.47)\end{array}$ & $\begin{array}{l}1.05^{* * *} \\
(4.34)\end{array}$ & $\begin{array}{l}1.65^{* * *} \\
(6.45)\end{array}$ \\
\hline 6. PRIMEAGE_YOUTH ${ }_{t-1}$ & $\begin{array}{l}0.688^{* *} \\
(1.99)\end{array}$ & $\begin{array}{l}1.57^{*} \\
(1.78)\end{array}$ & $\begin{array}{l}1.79 * * * \\
(2.51)\end{array}$ & $\begin{array}{l}1.84 * * \\
(2.26)\end{array}$ \\
\hline 7. PRIMEAGE_YOUTH_SQ ${ }_{t-1}$ & $\begin{array}{l}-0.372 * * \\
(-2.01)\end{array}$ & $\begin{array}{l}-0.821^{*} \\
(-1.70)\end{array}$ & $\begin{array}{l}-0.937 * * * \\
(-2.55)\end{array}$ & $\begin{array}{l}-1.02 * * * \\
(-2.44)\end{array}$ \\
\hline Real capital stock measure & No & No & Yes & Yes \\
\hline Observations & 336 & 336 & 208 & 208 \\
\hline Countries & 84 & 84 & 52 & 52 \\
\hline $\mathrm{R}^{2}$ & 0.32 & 0.46 & 0.43 & 0.74 \\
\hline
\end{tabular}

Notes: Balanced panel. GDP is always measured in its initial period to control for conditional convergence in growth estimates. All other independent variables are measured at their initial levels. The stock of physical capital $s_{k}$ is the investment share of GDP per capita in columns (1) and (2) and actual capital stock estimates in columns (3) and (4). The stock of human capital $s_{h}$ is the average years of schooling. Rate of population growth, technological efficiency and depreciation $(N+\theta+\sigma)$. The t-statistics are in parentheses.

*** Significant at $1 \%$ level, $* *$ significant at $5 \%$ level, *significant at $10 \%$ level.

demographic variables are all measured at their initial (one period lag) levels. ${ }^{16}$

\subsection{Baseline Fixed-Effect Estimates}

The within-group estimates in Table 2, column 1 imply that the first order effect of demographic ageing is decidedly positive with respect to 10 year per capita growth rates. Specifically, a 1 percent increase in WORKING_AGE - the ratio of persons aged 15-64 over the total population-increases economic growth by 0.539 percentage points over the course of a decade. Given that the 10 year

${ }^{16}$ The reason for doing so is that estimates that use period averages for the independent variables may not capture the possibility that the relationship between maturity and economic performance is largely spurious and the result of ex post migration decisions; i.e. working age persons may move from regions that are depressed to regions where the economy is strong. Part of this effect would indeed be picked up in our fixed effect panel estimation - since countries with persistently stronger economic performance would be captured by country $i$ 's fixed effect. A remaining portion of the migration impact would nevertheless remain since a temporary increase in economic performance in country $i$ might temporarily attract more working age persons and simultaneously lower the proportion of working age persons in slower growing country $j$. To mitigate the possibility of reverse causality, therefore, we measure WORKING_AGE and PRIME_AGE and all other variables at the beginning of each growth period rather than as decade averages. 
compound average GDP growth rate was 19.8 for the entire sample period, these impacts appear very small. However, if we calculate this first order effect using a more realistic increase in the ratio of working age persons, we get a slightly different picture. A 5 percent increase in the average number of persons aged 15-64 over the total population - which is equivalent to a 3 percentage point increase in the WORKING_AGE ratio-now leads to a more substantial 2.65 percentage point increase in the ten year growth rate. In terms of PRIMEAGE effects, we find that the ratio of prime age workers relative to youth has a positive effect on output growth up to a ratio 0.924 .

Next in column 2 we turn to estimates of per capita GDP levels. All else remains as before except that our conditional convergence term (i.e. initial level of GDP) used in our growth estimates is now expected to be positively associated with end of period of GDP levels, since rich countries tend to grow richer albeit at a slower rate (Hall and Jones, 1999). Apart from this change in sign, our specification is run with expectations as above.

The results are supportive of a positive first order and a curvilinear second order demographic ageing effect. The only difference is that our first order effect is larger-given that the mean of log per capita GDP in the sample was 8.48, the coefficient for WORKING_AGE of 2.32 corresponds to 26 percent of the difference in GDP per capita observed across countries. The turning point in our levels estimation for second order ageing is apparent once again; though slightly higher than for our growth estimates. Increases in the PRIME_YOUTH ratio beyond 0.956 (compared to 0.924) are associated with lower levels of per capita GDP.

Columns 3 and 4 repeat the same specifications as above, only replacing the investment share of GDP (which was always a proxy for the capital stock) with real capital stock data. Unfortunately, as noted earlier, this consistent series ends in 1990 and has a smaller set of countries. ${ }^{17}$ The smaller set includes an effective total (after missing data) of 52 countries, which includes all the OECD and a few remaining high quality data countries. One can think of this specification as being analogous to a sub-sample of OECD economies. The offsetting advantage of analyzing this smaller sub-sample with capital stock data is that institutionally these countries are much more similar than the entire sample, yet demographically they still differ quite significantly. This may help to isolate more precisely the effect of ageing on growth. The results in columns 3 and 4 , as judged by the $\mathrm{R}^{2}$, confirm that these estimates offer a far better prediction of model (5).

The results on our variables of interest show a much more robust and significant effect associated with capital accumulation and an effect which seemingly increases our estimates of first order demographic ageing. In column 3, the coefficient attached to WORKING_AGE now doubles in size to $1.05 .{ }^{18} \mathrm{~A} 5$ percent increase in the relative size of the working age population is associated with a 5.25

\footnotetext{
${ }^{17}$ The smaller set includes an effective sample of 55 countries, which by and large includes all the OECD and a few remaining high quality data countries. One can think of this specification having the more homogenous set of characteristics.

${ }^{18}$ This is not surprising since the OECD sample has experienced a relatively greater change in the structure of the working age population (see Figure 1 and Table 2) than in its relative size over the last 50 years.
} 
percentage point increase in the ten year growth rate (or close to a quarter of the overall average growth observed in the period averages). The increase in GDP growth rates associated with PRIME_YOUTH turns around the same ratio as before, 0.955 .

Column 4 shows the same specification as in column 2. Our results demonstrate again that the capital stock measure is an effective predictor of cross country differences in GDP. The effects on our demographic variables, though still significant at conventional levels, show a slight weakening in magnitude. Our WORKING_AGE coefficient is 1.65 (compared with 2.32 in our earlier estimate) and our turning point for PRIME_YOUTH is lower as well at 0.901 .

\subsection{Dynamic Panel Estimates}

As noted in our empirical approach discussion, neither the fixed-effects models just presented nor standard IV estimation can tackle the issue of potential high persistence of our national income dependent variables or any potential endogeneity associated with our right-hand side variables. The Arellano and Bond (1991) methodology addresses potential endogeneity with the use of appropriate instruments and allows one to account for the persistence of per capita GDP over time by including lagged GDP as a regressor. The country fixed-effect is eliminated by first-differencing and the set of valid instruments follows from the moment conditions with lagged variables. This has the advantage that all lagged values of the right-hand side covariates can be used as instruments for the first-differenced covariates.

In this subsection we therefore apply the difference-GMM estimator to our model of per capita GDP as outlined in equation (6). As several cross sections will be sacrificed when the differencing and lag structures associated with this estimation are used, we employ our unbalanced panel dataset, which includes more countries (greater sample depth) and also one more time period, 1950-2000 (greater sample length) to test our key findings.

In Table 3 we report difference-GMM estimates of our dynamic per capita GDP equations for our unbalanced dataset. We take our preferred estimation found in column (4) of Table 2 and use it ubiquitously here with the addition of time dummies as is recommended for unbalanced panels in dynamic estimations (Nickell, 1981; Arellano and Bond, 1991). ${ }^{19}$ Comparing columns (1) and (2) in Table 3, shows that the estimated coefficients on our variables of interest appear much the same across the unbalanced samples with and without the real capital stock variable. Both models appear well determined and have sensible long-run properties for a cross-country output equation. However, our demographic variables do change as a result of this dynamic estimation technique. Comparing the first difference coefficients for WORKING_AGE in column (1) of Table 3 with our corresponding preferred specification using the within-estimator in column (3)

\footnotetext{
${ }^{19}$ The unrestricted GMM estimator treats all variables (including the dependent variable) in first differences and lags the dependent variable one period. In doing so, two cross sections are lost so that the estimation period is 1970-2000 for our unbalanced panel.
} 
TABLE 3

Difference-GMM Estimates of Demographic Ageing and Economic Output Across Countries, 1970-2000; Dependent Variable is the First Difference of Log Real GDP PER CAPITA

\begin{tabular}{|c|c|c|c|c|}
\hline \multirow[b]{3}{*}{ Independent Variables } & \multicolumn{4}{|c|}{ GMM Estimates (all variables in first differences) } \\
\hline & \multicolumn{4}{|c|}{ Instrumenting Size of Effective Working Age Population† } \\
\hline & (1) & (2) & (3) & (4) \\
\hline \multirow{2}{*}{ 1. $\operatorname{Ln}\left(Y_{t-1}\right)$} & $0.522 * * *$ & $1.153 * * *$ & $0.747 * * *$ & $0.904 * * *$ \\
\hline & $(3.30)$ & $(4.89)$ & $(3.22)$ & $(4.11)$ \\
\hline \multirow{2}{*}{ 2. $\operatorname{Ln}\left(s_{k}\right)$} & $0.098 * * *$ & 0.006 & $0.109 * *$ & $0.094 *$ \\
\hline & $(3.02)$ & $(1.24)$ & $(2.13)$ & $(1.66)$ \\
\hline \multirow[t]{2}{*}{ 3. $\operatorname{Ln}\left(S_{h,}\right)$} & 0.010 & 0.073 & 0.061 & 0.048 \\
\hline & $(0.24)$ & $(1.43)$ & $(0.70)$ & $(0.38)$ \\
\hline \multirow{2}{*}{ 4. $\operatorname{Ln}(N+\theta+\sigma)$} & -0.991 & 0.282 & 4.201 & 3.391 \\
\hline & $(-0.30)$ & $(0.07)$ & $(0.67)$ & $(0.55)$ \\
\hline \multirow{2}{*}{ 5. LnWORKING_AGE } & $0.725 * *$ & $0.802 * * *$ & $4.617 * *$ & $4.564 * *$ \\
\hline & $(2.20)$ & $(2.70)$ & $(2.05)$ & $(1.92)$ \\
\hline \multirow{2}{*}{ 6. PRIMEAGE_YOUTH } & 0.566 & $1.26^{*}$ & $1.842 * *$ & $0.971^{*}$ \\
\hline & $(1.50)$ & $(1.72)$ & $(1.87)$ & (1.69) \\
\hline \multirow[t]{2}{*}{ 7. PRIMEAGE_YOUTH_SQ } & -0.188 & $-0.450^{*}$ & -0.555 & -0.271 \\
\hline & $(-1.28)$ & $(-1.69)$ & $(-1.51)$ & $(-1.36)$ \\
\hline $\begin{array}{l}\text { 8. Size of effective working } \\
\text { age population }\end{array}$ & No & No & Yes & Yes \\
\hline $\begin{array}{l}\text { 9. Real capital stock } \\
\text { measure }\end{array}$ & No & Yes & No & Yes \\
\hline Observations & 340 & 157 & 340 & 157 \\
\hline Countries & 96 & 55 & 96 & 55 \\
\hline Wald test & $242.28(10)$ & $176.92(9)$ & $280.88(17)$ & $256.92(14)$ \\
\hline Sargan test & $10.51(9)$ & $5.95(5)$ & $11.54(8)$ & $12.365(8)$ \\
\hline
\end{tabular}

Notes: Unbalanced panel. Effective working age replaces WORKING_AGE in row 5 in columns (3) and (4). This is the ratio of total participants in the labor market to total working age population. Time dummies are included in all equations. The stock of physical capital $s_{k}$ is the investment share of GDP per capita in columns (1) and (3) and actual capital stock estimates in columns (2) and (4). The stock of human capital $s_{h}$ is the average years of schooling. Rate of population growth, technological efficiency and depreciation $(N+\theta+\sigma)$. The t-statistics are in parentheses.

$\dagger$ We treat our "effective size of the working age population" variable in row 5 (which is the size of the working age population aged 15-64 relative to the total population) adjusted for participation rates) as endogenous in columns (3) and (4). Levels of the endogenous variables lagged two or more periods serve as instruments.

$* * *$ Significant at $1 \%$ level, **significant at $5 \%$ level, *significant at $10 \%$ level.

of Table 2, we see that the size of the first-order effect drops to 0.725 (compared to 1.05). The coefficient is still highly significant. By contrast the non-linear effect is not so accurately measured. The turning point is now much higher at 1.45 prime age workers for every younger worker, but significance level drops.

In column (2) the capital stock variable is added in place of investment share. Because the capital stock variable stops at 1990, we lose one more cross section and hence the panel runs from 1970 to 1990 . The WORKING_AGE effect of 0.802 is closer to our earlier estimate and the PRIME_YOUTH ratio and its square are jointly significant at the 10 percent level. The turning point of 1.37 is greater than our earlier estimates, most likely due to the time period in which fast growing economies were ageing and adding more prime age workers and fewer younger workers. 


\subsection{Dynamic Panel Estimates with Instrumented Working Age Variables}

It is important to note that our previous estimations did not control for the size of the economically active population. As such, we have estimated the effects - in terms of both size and structure - of the potentially active workforce on output, rather than these effects conditioned on the actual number of labor market participants (i.e. effective labor supply). We preferred these unconditioned UN population measures to the similar ILO dataset that adjusts for effective labor supply, primarily because participation rates are not as reliably measured across countries as is pure demographic data. Participation rates are also likely to suffer from potential endogeneity problems with respect to economic performance in a way that our pure demographic measures do not (i.e. persons usually re-enter the labor force when economic prospects improve). Fortunately, the Arellano-Bond estimator allows us to treat variables as endogenous and use levels lagged one or more periods as instruments.

In principle, therefore, the different channels through which population might impact growth, as described in Section 2, could be better captured by the relative size of the labor force than by the relative size of the working age population. Indeed, the choice between these two measures might not be irrelevant for the results since major changes in participation rates have been observed in the last four decades in many countries. The participation of women, for example, has significantly increased in many countries while that of people over 50 has dramatically fallen. Likewise, irregular participation in the labor market might be quite relevant in some developing countries. The use of the potentially active (as opposed to the active) working age population also poses the problem that this variable might be capturing not only supply-side effects, as outlined in our theoretical framework, but also demand-side effects related to differences in the composition of savings-expenditure by age group.

In order to see whether our results are robust to the inclusion of effective labor supply, in Table 3, column (3) using data from the ILO,${ }^{20}$ we substitute WORKING_AGE with this effective labor supply measure (i.e. the ratio of total participants in the labor market to total working age population). When including this regressor in our estimates, along with lags of levels used as instrumented variables, the results in columns (3) and (4) show a very large increase in first order demographic effects. The size of the participation adjusted working age population variable increases four-fold. Instrumenting tends to produce these increases, though even by IV estimates this increase is large but the estimate still carries a sensible interpretation. The estimates of our second-order demographic effects do change as well, but not significantly so. ${ }^{21}$ For example, the coefficients for primeyouth and prime-youth squared in column (3) are 1.84 and -0.55 respectively, meaning that economic output is first increasing and then decreasing in the ratio of prime-age workers to younger age workers. The overall relationship between country output and prime-youth ratio is rising when the ratio of prime-age workers (35-54) to young workers (15-34) is less than 1.67 and falls when the ratio

\footnotetext{
${ }^{20}$ This data is downloadable from http://laborsta.ilo.org/.

${ }^{21}$ Except for column 4 (where we are restricted to our sub-sample of countries with capital stock data and a smaller time period on account of the dynamic panel estimates).
} 
is over 1.67. Since the sample mean value of prime-youth ratio is 1.07 , for the average of country in our sample, prime-youth ratios have a generally positive effect on per capita country growth. ${ }^{22}$

\section{CONCLUSION}

This paper has focused on the response of per capita GDP growth to the process of population ageing as measured by changes in the proportion of working age workers across countries. We defined and estimated population ageing in two specific ways. First, in keeping with recent literature, a growing cohort of working age persons (those aged 15-64) was found to have a large positive effect on the ten year growth rate of GDP per capita. Second, we found that an increase in the number of prime age persons (aged 35-54) relative to the young working age population (aged 15-34) was found to have a positive but diminishing effect on per capita GDP growth. We estimated in a baseline estimate using fixed effects that the optimal ratio of prime age persons to youth is approximately 0.950 . Up to this point, the prime-youth ratio is positively related to growth but beyond this point it is negative. Given that the whole country sample in 2000 had a mean primeyouth ratio of 0.845 (see Table 1 , row 1), this means that for the majority of countries in our sample, increases in the prime-youth ratio lead to increases in real GDP per capita. However for OECD countries (see Table 1, row 2) that by 2000 already had average prime-youth ratios of 1.37 or more, the prime-youth ratio is likely acting as a drag on real GDP growth. Size of working age population remained positive throughout all the specifications.

We also take account of the dynamic nature of our panel data to control for potential endogeneity and persistence of both dependent and independent variables. The use of difference-GMM estimates initially produces results that are not too dissimilar to our fixed effects in signs and magnitudes of key variables, but our second order demographic effects are less precisely estimated. However, when we use GMM estimates that take account of the potential for endogeneity problems associated with our participation-rate adjusted estimate of working age population, the coefficients on our key demographic variables remain significant and the signs remain the same and as expected (see Table 3, columns (2) and (3)). Our overall results suggest that the process of population ageing produces intermediary changes to population age structure that can actually increase economic performance rather than dampen it.

\footnotetext{
${ }^{22}$ As an additional robustness check, we treated our working age population variable used in columns (1) and (2) of Table 3 as not strictly exogenous, using levels lagged one or more periods as instruments. These results are not presented but are available upon request. The results of these additional tests mirror the same specifications found in columns (1) and (2) of Table 3, and they indicate that treating working age population as predetermined makes it less difficult to reject the null hypothesis that the over identifying restrictions are valid, providing evidence that working age is better modeled as an exogenous variable as in Table 3, column (1).
} 


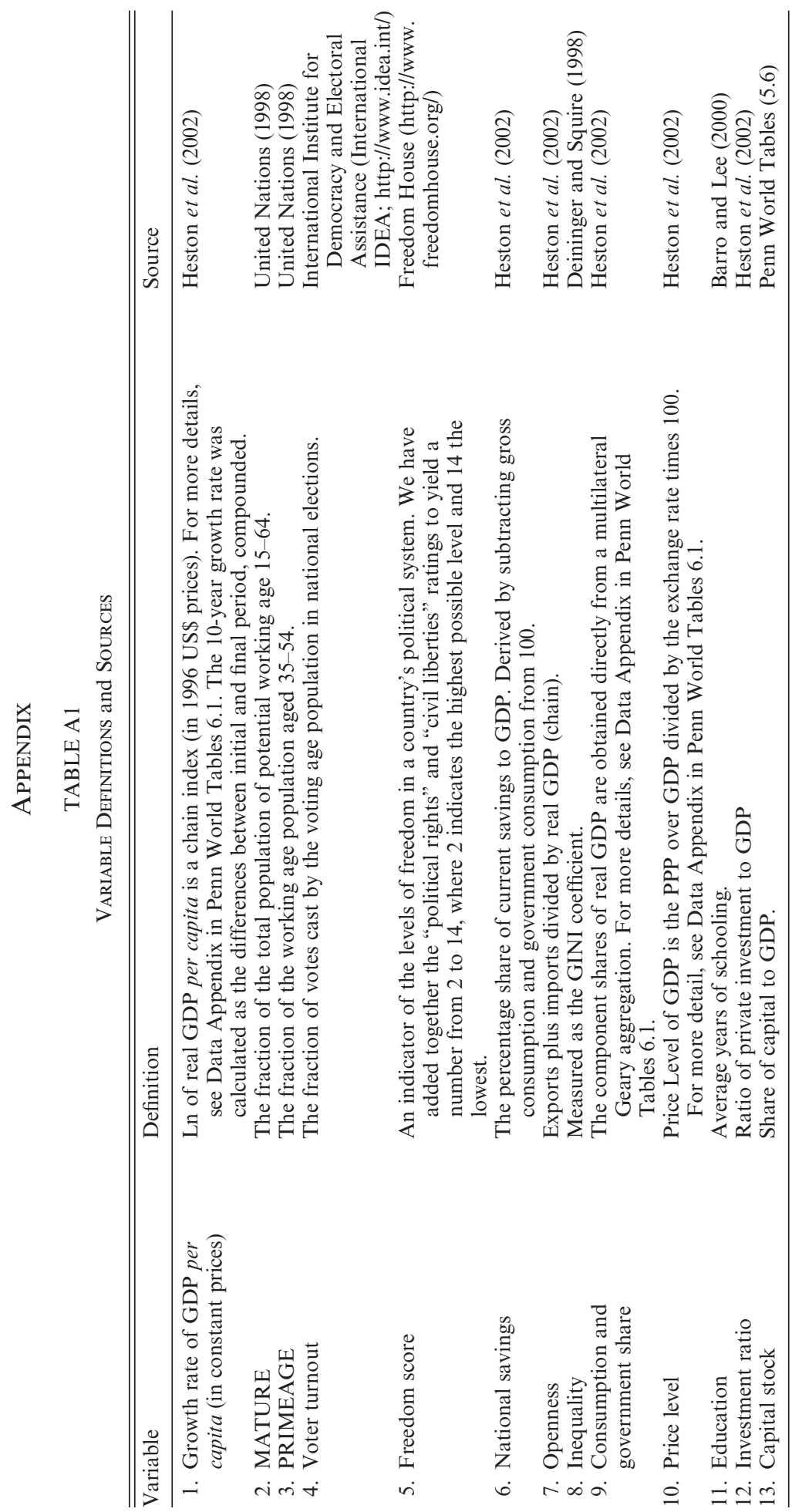




\section{REFERENCES}

Alesina, Alberto, Enrico Spolaore, and Romain Wacziarg, "Trade, Growth and the Size of Countries," in Philippe Aghion and Steven Durlauf (eds), Handbook of Economic Growth, North Holland, Amsterdam, 2003.

Arellano, M. and S. Bond, "Some Test of Specification for Panel Data: Monte Carlo Evidence and an Application to Employment Equations," The Review of Economic Studies, 58, 277-97, 1991.

Barro, Robert J. and Jong-Wha Lee, International Data on Educational Attainment: Updates and Implications, CID Working Paper No. 42, April 2000.

Barro, Robert and Xavier Sala-i-Martin, Economic Growth, McGraw-Hill, New York, 1995.

Bloom, David E. and David Canning, "How Demographic Change Can Bolster Economic Performance in Developing Countries," World Economics, 4(4), 1-14, 2003 a.

- "Contraception and the Celtic Tiger," Economic and Social Review, 34(3), 229-47, 2003 b.

Bloom, David E. and Pia Malaney, "Macroeconomic Consequences of the Russian Mortality Crisis," World Development, 26(11), 2073-85, 1998.

Bloom, David E. and Jeffrey G. Williamson, "Demographic Transitions and Economic Miracles in Emerging Asia," World Bank Economic Review, XII, 419-55, 1998.

Bloom, David E., David Canning, and Pia N. Malaney, "Demographic Change and Economic Growth in Asia," CID Working Papers, Vol. 15, Center for International Development at Harvard University, 1999.

Card, D., "The Causal Effects of Education on Earnings," in O. Ashenfelter and D. Card (eds), Handbook of Labor Economics, Vol. 3, 1801-63, 1999.

Deininger, Klaus and Lyn Squire, "New Ways of Looking at Old Issues: Inequality and Growth," Journal of Development Economics, LVII, 259-87, 1998.

Ermisch, John and Heather Joshi, "Demographic Change, Economic Growth and Social Welfare in Europe," CEPR Discussion Paper, CLXXIX, 1987.

Feyrer, James, "Demographics and Productivity," Department of Economics Working Paper, Dartmouth College, 2002.

Fougere, M. and M. Merette, "Population Ageing and Economic Growth in Seven OECD Countries," Economic Modelling, XVI, 411-27, 1999.

Galor, Oded and David N. Weil, "The Gender Gap, Fertility, and Growth," American Economic Review, LXXXVI, 374-87, 1996. , "Population, Technology, and Growth: From Malthusian Stagnation to the Demographic Transition and Beyond," American Economic Review, XC, 806-28, 2000.

Greenwood, Jeremy, Ananth Seshadri, and Guillaume Vandenbroucke, "The Baby Boom and Baby Bust: Some Macroeconomics for Population Economics," Economie d'Avant Garde Research Report, No. 1, University of Rochester, New York, 2002.

Hall, Robert and Charles I. Jones, "Why Do Some Countries Produce So Much More Output per Worker than Others?" Quarterly Journal of Economics, CXIV, 83-116, 1999.

Heston, Alan, Robert Summers, and Bettina Aten, Penn World Table Version 6.1, Center for International Comparisons at the University of Pennsylvania (CICUP), October 2002.

Jones, Charles I., "Population and Ideas: A Theory of Endogenous Growth," in Phillipe Aghion, Roman Frydman, Joseph Stiglitz, and Michael Woodford (eds), Knowledge, Information, and Expectations in Modern Macroeconomics: In Honour of Edmund S. Phelps, Princeton University Press, New Jersey, 2003.

Keynes, John M., "Some Economic Consequences of a Declining Population," Eugenics Review, LX, 91-109, 1937.

Kosai, Yutaka, Jun Saito, and Naohiro Yashiro, "Declining Population and Sustained Economic Growth: Can They Coexist?” American Economic Review, 88(2), 412-16, 1998.

Kremer, Michael and Jim Thomson, "Young Workers, Old Workers and Convergence," Journal of Economic Growth, III, 5-28, 1998.

Krueger, Alan and Jorn-Steffen Pischke, "A Comparative Analysis of East and West German Labor Markets Before and After Unification,” NBER Working Paper, W4154, 1992.

Lazear, Edward P. and Richard B. Freeman, "Relational Investing: The Worker's Perspective,” NBER Working Paper, W5436, National Bureau of Economic Research, 1996.

Lemieux, Thomas, Schooling, Experience and Earnings: Twenty Five Years of 'Mincer' Equations, Department of Economics, University of British Columbia, 2003.

Mankiw, Gregory N., David Romer, and David Weil, "A Contribution to the Empirics of Economic Growth," Quarterly Journal of Economics, CVII, 407-37, 1992.

Mason, Andrew, Sang-Hyop Lee, and Gerard Russo, "Demography of Aging Across Asia," in H. Yoon and J. Hendricks (eds), Handbook of Asian Aging, Baywood Publishing Co., Amityville, NY, 2008 . 
Mincer, Jacob, Schooling, Experience and Earnings, National Bureau of Economic Research, New York, 1974.

Modigliani, Franco, "Life Cycle, Individual Thrift, and the Wealth of Nations," American Economic Review, LXXVI, 297-313, 1986.

Modigliani, Franco and Albert Ando, "The life-Cycle Hypothesis of Savings: Aggregate Implications and Tests," American Economic Review, LIII, 55-84, 1963.

Neumark, David, "Employers' Discriminatory Behavior and the Estimation of Wage Discrimination," Journal of Human Resources, XXIII, 279-95, 1988.

Nickell, S., "Biases in Dynamic Models with Fixed Effects," Econometrica, 49, 1417-26, 1981.

Shimer, Robert, "The Impact of Young Workers on the Aggregate Labor Market," Quarterly Journal of Economics, CXVI, 969-1007, 2001.

Simon, Julian, Theory of Population and Economic Growth, Basil Blackwell, Oxford, 61-79, 1986.

Summers, Robert and Allen Heston, "The Penn World Tables (Mark 5): An Expanded Set of International Comparisons 1950-1988," Quarterly Journal of Economics, CVI, 327-68, 1991.

Temple, Jonathan, "The New Growth Evidence," Journal of Economic Literature, XXXVII, 112-56, 1999.

United Nations, World Population Prospects 1950-2050, United Nations, New York, 1998.

Weinberg, Bruce A., "Experience and Technology Adoption," Ohio State University, Working Paper 1051, 2002.

Willis, R. J., "Wage Determinants: A Survey and Re-Interpretation of Human Capital Earnings Functions," in O. Ashenfelter and R. Layard (eds), Handbook of Labor Economics, Vol. 1, 525-602, 1986. 